following results are observed-(a) the lowest mortality amongst the lying-in is 5.4 per 1000 , the highest 123 per 1000 , that in our own country being about $45 ;(b)$ the system has not resulted in removing the anqualified practitioner from the poor, who practises as she does in this country; (c) the midwives do not, as a matter of fact, although required to do so by law, send for the surgeon for the repair of the perineum - in fact, they do not send for medical assistance unless compelled to do so in extremity. 2. That although the Obstetrical Society has over 2000 midwives on its bjoks, these persons are not found to be generally practising amongst the poor unless employed by institutions or charities. 3. That certified midwives have been found gailty of criminal practices.

I will now call attention to the case of the certificated midwife, mentioned in THE LANCET of Feb. 9th, as showing some of the dangers which are likely to be the result of the action of the Obstetrical Society. It appears to me that the obstetricians of note, so far from promoting the interests of humanity, with the best intentions in the world, have done and are doing just the reverse. The Royal College of Physicians of London cannot escape some responsibility in the matter. Just before the meeting of the Select Committee of the House of Commons it issued a report on the subject of midwives' registration. The medical profession, no doubt, knowing the propensity of the College for being at least a quarter of a century behind the times, did not pay much attention to it, but it carried weight before the Select Committee. In this report allusion is made to the fact that in Continental countries midwives practised under State control. The College could not be expected to ascertain the results obtained under such a system ; indeed, there was no information availab?e relating to all foreign countries until the return on stillbirths was published, and, as Dr. Farcuharson admitted when I was giving evidence before the Select Committee, their committee could not be expected to sit more than two or three times. It could not in view of the composition of the committee and the old-world ways of the College, but it does not follow that a reasonable conclusion could possibly be arrived at by such procedure. If accoucheurs of note will kindly enlighten our darkness on any or all of these points I am sure they will delight an admiring profession, which at present fails entirely to see the reasonableness of their course of action.

I am, Sirs, your obedient servant, Hatfield, Feb. 10th, 1895. LOVell Drage.

\section{"THE DENTIST'S EDUCATION."}

\section{To thi Editors of THE LANCET.}

SIRS,-The examination of candidates for the L.D.S. of the Royal College of Surgeons of England has long been a grievance with dental teachers. Beyond the introduction of the "practical" portion in 1879 no other improvement of any moment has taken place in the examination since 1872 , when written papers were given in addition to the viv $\hat{a}-v o c e$. all the other licensing corporations-Edinburgh, Glasgow, and Dublin-have their primary and final examinations at two periods of the dental student's career. But in this matter the Royal College of Sargeons of Fngland remained stationary, apparently fixed, notwithstanding the utterances of teachers and others, many times repeated from 1879, urging that the examination in the general subjects of the curriculum-at all events, anatomy and physiology-be taken at a different time from that of certain of the special subjects-dental surgery \&c. Not only Foud such a division of the examination reduce the tendency to "cram," which the existing single examination in all the sobjects fosters, but the onus of preparing the candidates in aratomy and physiology would rest upon the teachers of those sciences at the general medical schools and not, as heretofore and at present, upon the tutors of the dental schools-a preposterous anomaly which ought not to exist. Regarding the question of adding another-a third-year to the hospital portion of the dental curriculam referred to by $\mathrm{Mr}$. Newland-Pedley in THE LAXCET of Feb. 2nd I shall not discass it now; but I Fonld emphasise this fact, that the marked superiority of the Britich over the American dentist's education has hitherto corisisted in the better theoretical groundwork and knowledge of the former. Our "cousins" are, however, advancing in this respect and that markedly, and if we are to maintain that higher standard the Royal College of Surgeons of Rngland-the licensing corporation that admits to the pro- fession the majority of the recruits-should not lose any of its dental examinations.

I am, Sirs, yours faithfully,

$$
\text { THOMAS GADDES, }
$$

late Dean of the National Dental College, London, and also of the Dental Department of the

Harrogate, Feb. 6th, 1895. University of Denver, U.S.A.

\section{"THE DEBATE ON THE NATURE AND TREATMENT OF PERITONITIS AT THE OBSTETRICAL SOCIETY."}

\section{To the Editors of TH国 LANCET}

Sins, -As the author of the paper which has been the occasion of such lively correspondence the last two or three weeks, will you grant me space for a few remarks? Nothing impressed mo more at the debate than the antagonism of the riews advanced by different speakers eren on a mere question of fact; whetber, for example, a certain case was or was not a case of peritonitis. The letter of $\mathrm{Mr}$. Emmett in your last week's issue has, to my mind, the right ring about it. The mortality in his obstetric practice, from conditions which he had been wort to regard as due to peritonitis, has diminished since his adoption of the purgative treatment to the vanishing point. $\mathrm{My}$ adrocacy of the employment of purgatives in peritonitis rest apparently on entirely different grounds from those maintained by Mr. Lawson Tait; but wheth $x$ one theory or the other, or neither, is correct matters, after all, but little. Truth is not absolute and final, much less can the statement of a truth be. Let the profession put the treatment advocated to a practical test. For the other suggestions in my paper I do earnestly beg the like consideration. Firstly, the regular washing out of the stomach until the bowels can be got to act; secondly, the support of the beart strength and kidney activity by the administration of strychnia and digitalin: and, thirdly, inbalations of oxygen with the object of increasing the oxidising power of the blood. I am, Sirs, jours obediently, Queen Anne-street, W., Feb. 11th, $1895 . \quad$ JoHN SHAW.

\section{To the Eaitors of THE LANCET.}

Sins, - Many, like myself, are gratefal to the man who has helped us so much to bring our abdominal operations to a successful termination. It seems to me that it is a very small and cheap notoriety that is to be obtained by attacking a man on what Mr. Richard Emmett well describes as a verbal quibble. Surely Mr. Lawson Tait may be allowed to treat such attacks with contemptuous silence. We all know perfectly well what Mr. Tait means when he says that the removal of distension prevents peritonitis, and if he has at some time expressed this in terms which might lend them selpes to a different constructinn it ill becomes anyore to be continually carping at him. It is not too much to say that many hundreds of lives have been saved by the adoption of Mr. Tait's purgative treatment of distension, and that abdominal surgery owes its position to-day in a great measure to his boldness and teaching.

I am, Sirs, yours faithfally,

Huddersfield, Feb. 13th, 1895.

T. Kilner Clarke.

\section{THE TREATMENT OF DIPHTHERIA.}

\section{To the Editors o THE LANCET.}

SIBS, - I observe that in the comparisons now being drawn between the results of the antitoxin treatment of diphtheria and those obtained by the old methods the writers have referred to only two remedies as being used in combating the disease-namely, the perchloride of iron and chlorate of potassium with hydrochloric acid. I have seen no mention made of a preparation which in my hanc's has had a marked effect in arresting the exudation of membrane on the fauces. I allude to the euchlorine solution first employed as a remedy for scarlatina anginosa and eulogised by Sir Thomas Watson in his lectures on the Practice of Pbycic. For more thar twenty years I have used the solution, made according to the formula given in the lectures, in cases of diphtheria, and 1 may say with a success nearly comparable to that obtained with antitoxin serum in the metropolitan hospitals. In fact. 